\title{
Maximum power per VA control of vector controlled interior permanent magnet motor
}

\author{
THAKUR SUMEET SINGH*D and AMIT KUMAR JAIN
}

\begin{abstract}
Department of Electrical Engineering, Indian Institute of Technology Delhi, New Delhi 110016, India
\end{abstract}
e-mail: sumeet.nitw@gmail.com

MS received 25 September 2016; revised 4 June 2017; accepted 18 January 2018; published online 11 April 2018

\begin{abstract}
Maximum Torque Per Ampere is the commonly used technique for operating interior permanent magnet (IPM) motor while little work is reported towards maximum power-factor operation i.e., Maximum Power Per Volt-Ampere (MPVA). The MPVA operation allows maximum-utilization of the drive-system. The control technique is developed using detailed mathematical model of IPM motor in MPVA, and the solution to the quartic equations involved is derived and analyzed. The solution is utilized to develop LUT for implementation of MPVA control. The comparison of MTPA and MPVA technique is established to demonstrate its merits and demerits. The proposed algorithm is supported by simulation and experimental results on a $5.5 \mathrm{KW}$ vector controlled IPM drive.
\end{abstract}

Keywords. Permanent magnet motor; unity power factor; maximum VA utilization; current minimization.

\section{Introduction}

Interior Permanent Magnet (IPM) motors have gained vast importance due to their high power density and deep field weakening capability. These motors have inset-magnets which introduce inverse-saliency in the motor structure. This results in saliency component of torque in addition to the torque component due to Permanent Magnet (PM). The presence of both PM and saliency torque make the motor control complicated if operated under optimization techniques. Control strategies of IPM motor have been wellestablished [1-21]. The most widely used control is Maximum Torque Per Ampere (MTPA) [1-4] or current minimization control which aims at minimizing current vector for a required torque command. Jahns et al [1] introduced normalization to eliminate motor parameters from the MTPA algorithm and has demonstrated the flux-weakening operation of IPM motor in [2]. Morimoto et al [3] proposed high-performance current regulator that compensates current and voltage limits. Bon-Ho and Nitin et al [4] utilized torque-flux quantities to control the IPM motor using a 2Dlookup table based approach which incorporates dc-link variation and parameter uncertainty. Sung-Yoon et al [5] proposed online-computation based solution of the 4th order quartic equations rather than look-up table approach for better accuracy. The current minimization control is explained in great detail with the solutions provided for the quartic equations involved. Lee et al [6] demonstrated a loss-minimization control followed by use of polynomial

*For correspondence approximations. Algio et al [7] proposed energy saving scalar control for industrial drives.

In literature, little work is reported for operation of IPM motor at Unity Power Factor (UPF). Operation at UPF would enable full utilization of the machine ratings and the inverter. Also, operation under UPF would enable extended constant torque region up to a higher speed. Schiferl et al [8] analyzed in detail the power capability of salient pole Permanent Magnet Synchronous Motors (PMSM). They have also explained the effect of saliency ratio on the power capability of salient pole (IPM) motors. Moussa et al [9] looked into the UPF operation of PMSMs. They have explained to an extent, the UPF operation of both salient and non-salient PM motors and simulation results for surface-mounted PM motor under UPF are provided.

Detailed mathematical analysis of the 4th order quartic equations involved for IPM motor operated at UPF has not been looked into in the past. Also, the UPF operation of IPM motor has not been demonstrated experimentally. Present day control strategies of IPM motor focus on the current minimization technique i.e., MTPA and loss minimization while, Maximum VA utilization control has not been looked into in detail. The motor operation under UPF would be along Maximum Power Per Volt-Ampere (MPVA). The control along MPVA technique allows maximum utilization of the IPM motor.

Control of IPM motor is complicated due to the presence of 4th order polynomials and therefore, Look Up Table (LUT) based control is preferred. The MTPA control strategy is implemented either, by 1D-LUT [1], or by use of online-computation [5]. The reduction in dc-link voltage or 
the increase in the operating speed or both may require operation in Field Weakening (FW). The operating point when IPM motor is under FW is decided by the operating speed, the load torque, the dc-link voltage (voltage-limit locus) and the current limit locus. For this reason, FW operation requires either a 2D-LUT based control [4] or online-computation based control [5] and is complicated in comparison to the control along MTPA, where the point of operation is decided only by the load torque.

The operation along MPVA, in comparison to MTPA technique, facilitates extended constant torque region i.e., up to a higher operating speed, without the need to enter field-weakening. Therefore, the complicated operation in FW is avoided up to a higher operating speed. It is to be noted that, though the MPVA control enables operation at higher speed, the maximum torque is slightly reduced. In this work, the MTPA technique and the proposed MPVA control technique, are compared in detail. The power-capability curves of both the control techniques are analyzed. Also, the operation in MPVA has higher peak-power capability at rated operating condition in comparison to MTPA.

The proposed MPVA control technique is explained and detailed mathematical model for MPVA operation is established. The solution to 4th order polynomials involved under MPVA operation is derived and analyzed in detail. MPVA control technique is supported by simulation and experimental results. This paper is organized as follows. The mathematical model of IPM motor is given in section 2. The operating regions of IPM motor i.e., MTPA, Maximum Torque Per Voltage (MTPV) and MPVA are shown in section 3. The power capability curve under MPVA and MTPA technique is also explained. In section 4, the solution for quartic-equation involved for operation along MPVA is derived and analysed. Section 5 describes the control algorithm and is supported by simulation results in section 6 . The experimental results are provided in section 7 . The conclusins are provided in section 8 .

\section{Mathematical model of IPM motor}

Mathematical model of motor is necessary to understand its operation. The IPM motor can be expressed using the following set of differential equations [1]:

$$
\begin{gathered}
v_{q d s}=r_{s} i_{q d s}+\omega_{e} \lambda_{d q s}+p \lambda_{d q s} \\
\left(\lambda_{d q s}\right)^{T}=\left[\begin{array}{ll}
\lambda_{d s} & -\lambda_{q s}
\end{array}\right] \\
\lambda_{q d s}=\left[\begin{array}{cc}
L_{l s}+L_{m q} & 0 \\
0 & L_{l s}+L_{m d}
\end{array}\right]\left[\begin{array}{l}
i_{q s} \\
i_{d s}
\end{array}\right]+\lambda_{m}\left[\begin{array}{c}
0 \\
1.5
\end{array}\right]
\end{gathered}
$$

The transformations used here are:

$$
\begin{aligned}
& v_{q d s}=\left(\begin{array}{ll}
v_{q s} & v_{d s}
\end{array}\right)^{T}=\left[\begin{array}{cc}
-\sin \left(\theta_{e}\right) & \cos \left(\theta_{e}\right) \\
\cos \left(\theta_{e}\right) & \sin \left(\theta_{e}\right)
\end{array}\right] \\
& {\left[\begin{array}{ccc}
\frac{3}{2} & 0 & 0 \\
0 & \frac{\sqrt{3}}{2} & -\frac{\sqrt{3}}{2}
\end{array}\right]\left[\begin{array}{c}
v_{a s} \\
v_{b s} \\
v_{c s}
\end{array}\right]} \\
& i_{q d s}=\left(\begin{array}{ll}
i_{q s} & i_{d s}
\end{array}\right)^{T}=\left[\begin{array}{cc}
-\sin \left(\theta_{e}\right) & \cos \left(\theta_{e}\right) \\
\cos \left(\theta_{e}\right) & \sin \left(\theta_{e}\right)
\end{array}\right] \\
& {\left[\begin{array}{ccc}
\frac{3}{2} & 0 & 0 \\
0 & \frac{\sqrt{3}}{2} & -\frac{\sqrt{3}}{2}
\end{array}\right]\left[\begin{array}{l}
i_{a s} \\
i_{b s} \\
i_{c s}
\end{array}\right]}
\end{aligned}
$$

Note: A factor of 1.5 is seen due to the transformations used being not quantity equivalent.

$$
T_{e}=\frac{2}{3} \frac{P}{2}\left[1.5 \lambda_{m} i_{q s}+\left(L_{d}-L_{q}\right) i_{q s} i_{d s}\right]
$$

\section{Operation trajectories of IPM motor}

The operating point is decided by the motor speed and torque required, and is limited by the motor rating.

a. The current limit of the motor can be given by

$$
i_{d s}^{2}+i_{q s}^{2} \leq i_{s \_r}^{2}
$$

b. Voltage/Flux limit can be given as (resistance drop neglected)

$$
L_{q}^{2} i_{q s}^{2}+\left[L_{d} i_{d s}+1.5 \lambda_{m}\right]^{2} \leq \lambda_{s \_r}
$$

c. MTPA is described by [1]:

$$
\begin{gathered}
T_{e}=\frac{2}{3} \frac{P}{2}\left(L_{q}-L_{d}\right)\left(\sqrt{i_{d s}\left(i_{d s}-\frac{1.5 \lambda_{m}}{L_{q}-L_{d}}\right)^{3}}\right) \\
T_{e}=\frac{2}{3} \frac{P}{2}\left(1.5 \lambda_{m}\right) i_{q s} \\
\left(\frac{1}{2} \pm \frac{1}{2} \sqrt{1+4\left(\frac{i_{q s}\left(L_{q}-L_{d}\right)}{1.5 \lambda_{m}}\right)^{2}}\right)
\end{gathered}
$$

d. MTPV/Maximum Torque per Minimum Flux (MTPF) is described by:

$$
i_{q s}= \pm \sqrt{\left(\frac{V_{d q}}{\omega_{e} L_{q}}\right)^{2}-\left(\frac{L_{d} i_{d s}+1.5 \lambda_{m}}{L_{q}}\right)^{2}}
$$




$$
\begin{aligned}
i_{d s}= & \frac{1.5 \lambda_{m}}{L_{q}-L_{d}}\left[\left(\frac{-(3 \rho-4)}{4}\right)\right. \\
& \left.-\frac{1}{4} \sqrt{\left\{(\rho-2)-(\rho-1)\left(\frac{V_{d q}}{1.5 \lambda_{m} \omega_{e}}\right)^{2}\right\}}\right]
\end{aligned}
$$

where,

$$
\begin{gathered}
\lambda_{b}=1.5 \lambda_{m}, \rho=\frac{L_{q}}{L_{d}}, \text { and } \\
\lambda_{s}=\frac{V_{d q}}{\omega_{e}}=\frac{\sqrt{\left(v_{q s}\right)^{2}+\left(v_{d s}\right)^{2}}}{\omega_{e}}
\end{gathered}
$$

e. The UPF operation is defined by the relation:

UPF is obtained when the vector $i_{\mathrm{s}}$ and $\mathrm{v}_{\mathrm{s}}$ are in phase. The condition for UPF is:

$$
\tan ^{-1} \frac{i_{q s}}{i_{d s}}=\tan ^{-1} \frac{v_{q s}}{v_{d s}} \Rightarrow \frac{i_{q s}}{i_{d s}}=\frac{v_{q s}}{v_{d s}}
$$

using, (15) and (1), under steady state [9]:

$$
i_{d s}=\frac{1}{2}\left(\frac{-1.5 \lambda_{m}+\sqrt{\left(1.5 \lambda_{m}\right)^{2}-4 L_{d} L_{q} i_{q s}^{2}}}{L_{d}}\right)
$$

The relation (16) is important which defines the operation at UPF. The vector control of IPM motor would require relation between $T_{e}-i_{d s}$ and $T_{e}-i_{q s}$ which would be difficult to obtain using (16). Also, the LUT developed using (16) would not be of equal intervals in $T_{e}$ which poses difficulty in practical implementation and accuracy. Thus detailed analysis of UPF operation is required.

The operation trajectories are shown in figure 1 in $\mathrm{i}_{\mathrm{ds}^{-}}$ $\mathrm{i}_{\mathrm{qs}}$ reference frame. The rated operating point under MTPA is indicated by ' $\mathrm{A}$ ' and rated operating point under MPVA is indicated by ' $\mathrm{B}$ '. The power capability curves when the IPM motor is operated along MTPA is shown in figure 2(a), and when operating along MPVA technique is shown in figure 2(b). As seen in figure 2(a), the operation along MTPA has non-unity power factor whereas, the operation following MPVA technique (figure 2b) is at UPF. The peak power point 'B', for operation along MTPA, lies in the field weakening region. On the other hand, for motor control along MPVA technique, as ' $\mathrm{B}$ ' lies on MPVA trajectory, peak power can be extracted without the need to enter field-weakening. Also, though the operation along MPVA has 15\% lower maximum torque in comparison to MTPA, the MPVA operation provides extended constant torque region up to $295 \mathrm{rad} / \mathrm{s}$ as compared to $230 \mathrm{rad} / \mathrm{s}$ obtained under MTPA technique. At speeds lower than $230 \mathrm{rad} / \mathrm{s}$, the maximum power is $15 \%$ lower along MPVA. But, as the MPVA

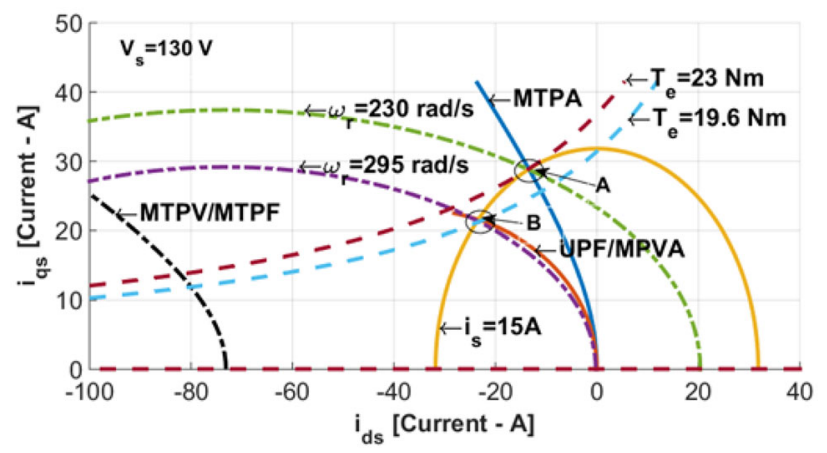

Figure 1. Operation trajectories of IPM.

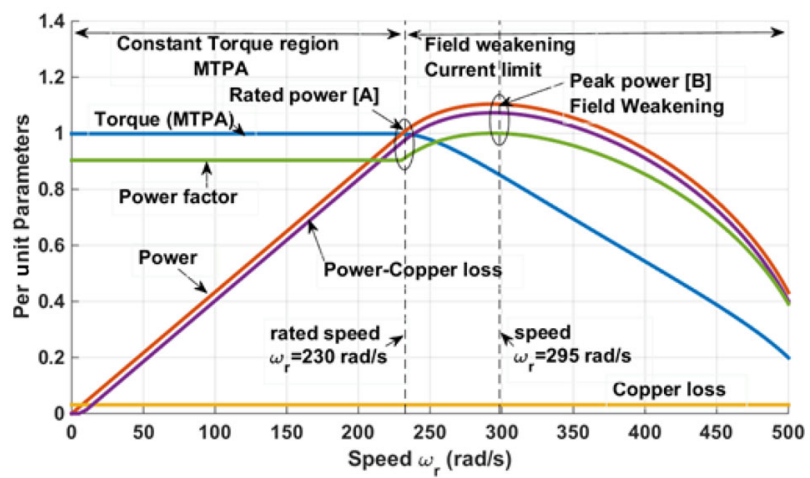

(a)

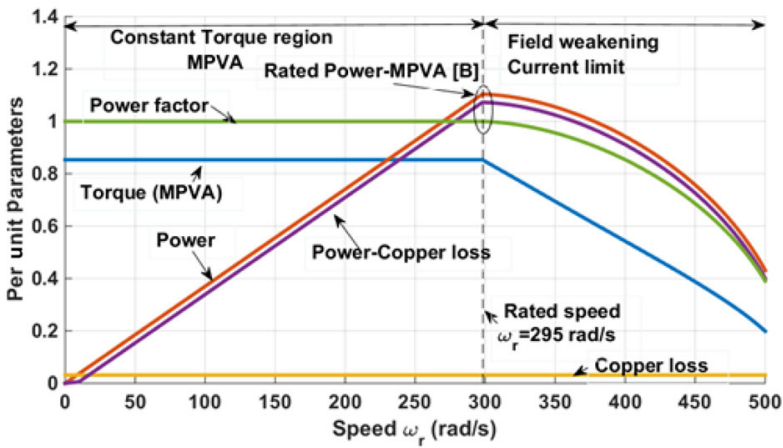

(b)

Figure 2. Peak power, torque and power factor characteristics of IPM motor under (a) MTPA and (b) MPVA.

facilitates $28.2 \%$ higher operating speed, the operation at point 'B' [MPVA] has $10 \%$ more power as compared to operation at point ' $A$ ' [MTPA].

\section{Solution to UPF quartic polynomial}

Equation (16) is utilized to a derive a solution in terms of direct and quadrature axis currents $i_{\mathrm{ds}}$ and $i_{\mathrm{qs}}$, which can be used either for online-computation based implementation of UPF/MPVA controlled IPM motor or to develop LUT. Substituting the UPF relation (16) in torque expression (6): 


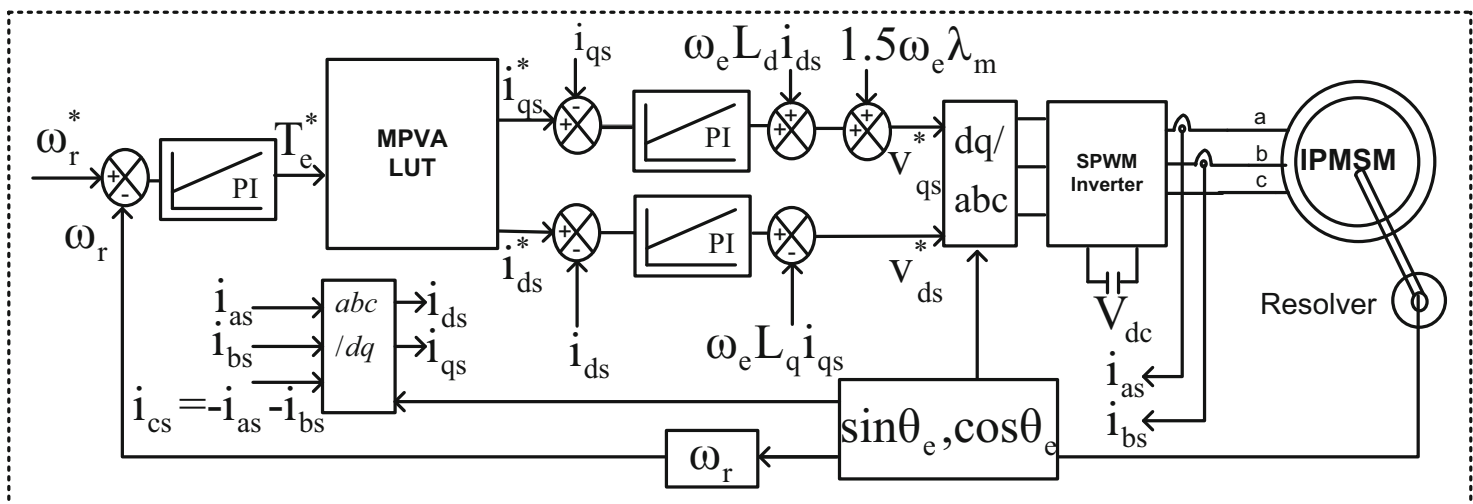

Figure 3. Control block diagram for Vector Controlled IPM motor.

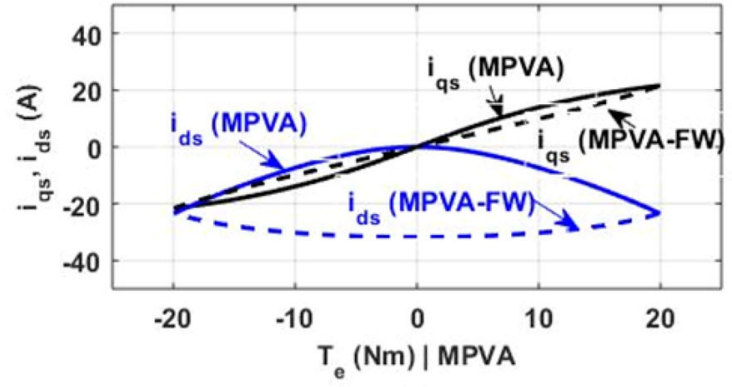

(a)

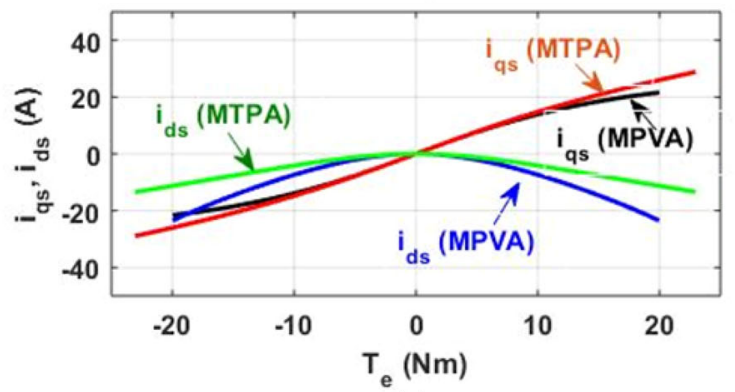

(c)

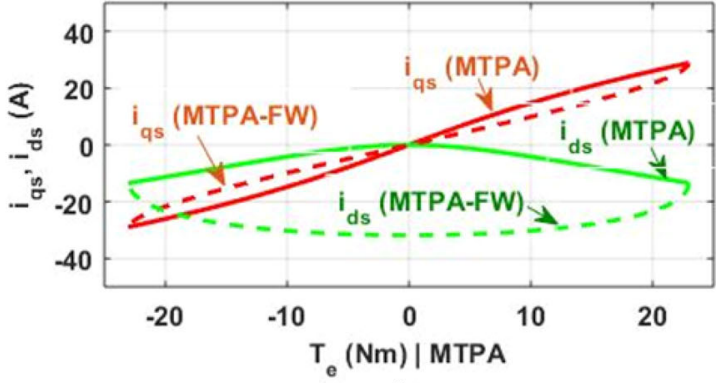

(b)

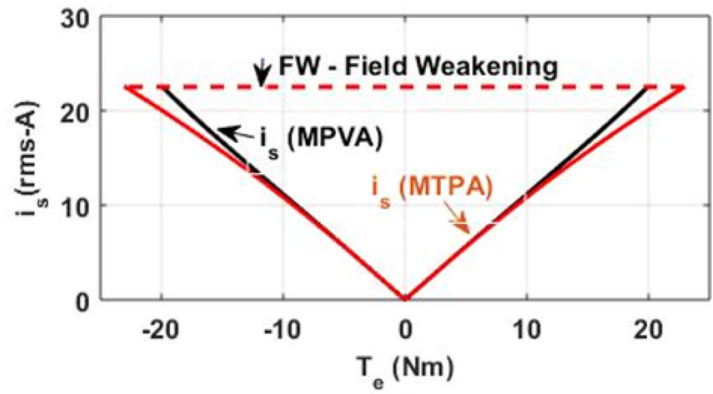

(d)

Figure 4. Relation of torque and current for MTPA and MPVA. (a) Currents $i_{\mathrm{ds}}$ and $\mathrm{i}_{\mathrm{qs}}$ variation with developed torque Te for MPVA, (b) currents $i_{\mathrm{ds}}$ and $\mathrm{i}_{\mathrm{qs}}$ variation with developed torque Te for MTPA, (c) comparison of currents $i_{\mathrm{ds}}$ and $\mathrm{i}_{\mathrm{qs}}$ variation with developed torque Te for MTPA and MPVA, and (d) comparison of current magnitude with developed torque for MTPA and MPVA.

The quartic expression in terms $\mathrm{i}_{\mathrm{qs}}$ is obtained:

$$
\begin{aligned}
\Rightarrow & 4 i_{q s}^{4}(1-\rho)^{2} L_{d} L_{q}+4 i_{q s}^{2} \lambda_{b}^{2} \rho-i_{q s} \frac{12 T_{e} \lambda_{b}(1+\rho)}{P} \\
& +\left(\frac{6 T_{e}}{P}\right)^{2}=0
\end{aligned}
$$

$$
\begin{aligned}
& a i_{q s}^{4}+b i_{q s}^{3}+c i_{q s}^{2}-d i_{q s}+e=0, \quad \text { where } \\
& a=4(1-\rho)^{2} L_{d} L_{q}, b=0, c=4 \lambda_{b}^{2} \rho, \\
& d=\frac{-12 T_{e} \lambda_{b}(1+\rho)}{P}, \text { and } e=\left(\frac{6 T_{e}}{P}\right)^{2}
\end{aligned}
$$

Expression (17) is solved by using the general quartic solution:
Determinant of the above expression is given as: 

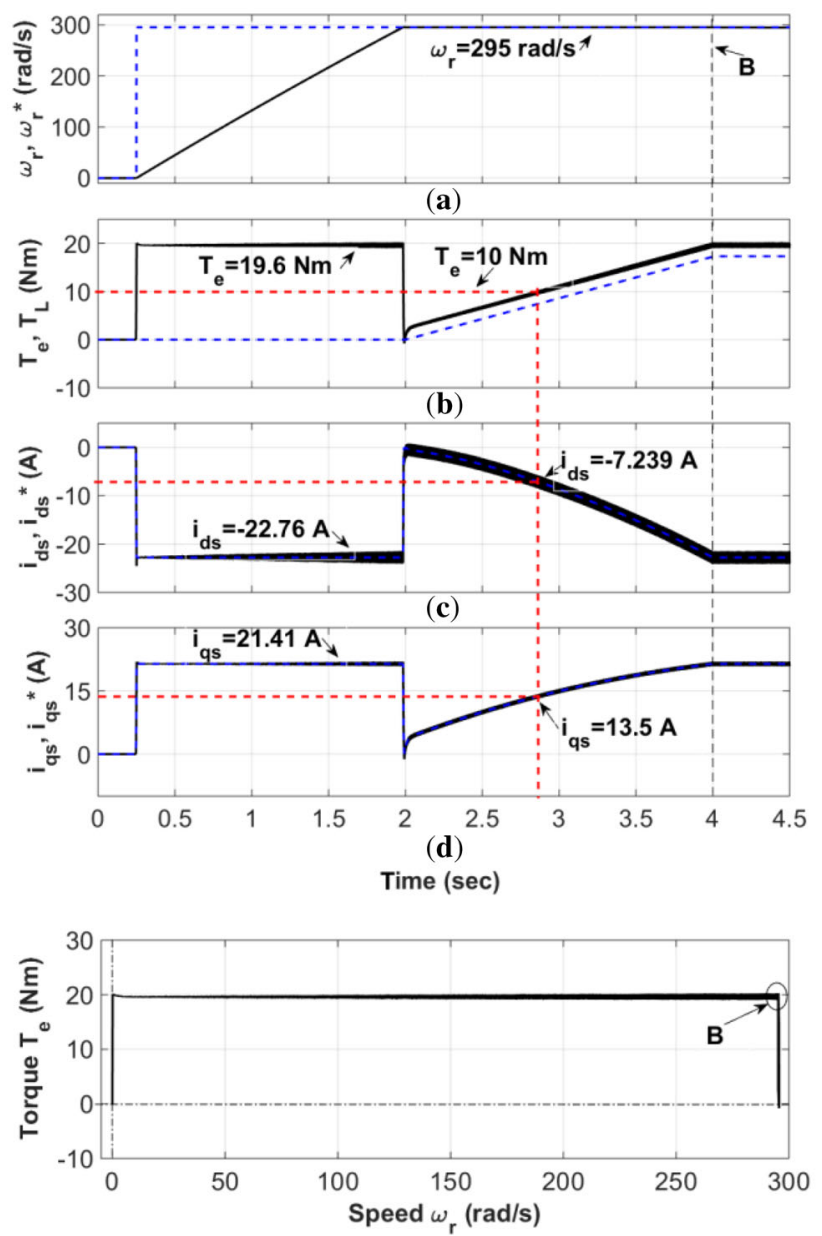

(e)

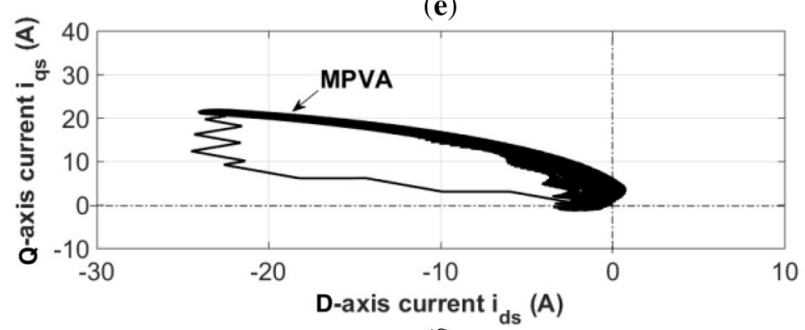

(f)

Figure 5. Simulation results following MPVA control technique. (a) Speed $\omega_{\mathrm{r}}$ and speed reference $\omega_{\mathrm{r}}{ }^{*}$, (b) Developed torque $\mathrm{T}_{\mathrm{e}}$ and load torque $\mathrm{T}_{\mathrm{L}}$, (c) d-axis current $\mathrm{i}_{\mathrm{ds}}$ and reference $\mathrm{i}_{\mathrm{ds}}{ }^{*}$, (d) q-axis current $\mathrm{i}_{\mathrm{qs}}$ and reference $\mathrm{i}_{\mathrm{qs}}{ }^{*}$, (e) Torque-speed characteristics, and (f) $\mathrm{i}_{\mathrm{ds}}-\mathrm{i}_{\mathrm{qs}}$ trajectory followed [MPVA].

$$
\begin{aligned}
\Delta= & 256 a^{3} e^{3}-192 a^{2} b d e^{2}-128 a^{2} c^{2} e^{2}+144 a^{2} c d^{2} e \\
& -27 a^{2} d^{4}+144 a b^{2} c e^{2}-6 a b^{2} d^{2} e-80 a b c^{2} d e \\
& +18 a b c d^{3}+16 a c^{4} e-4 a c^{3} d^{2}-27 b^{4} e^{2} \\
& +18 b^{3} c d e-4 b^{3} d^{3}-4 b^{2} c^{3} e+b^{2} c^{2} d^{2}
\end{aligned}
$$

Substituting a, b, c, d, and e gives:

$$
\begin{aligned}
\Delta= & \frac{764411904 L_{d}^{3} L_{q}^{3} T_{e}^{6}(\rho-1)^{6}}{P^{6}} \\
& -\frac{214990848 L_{q}^{4} T_{e}^{4} \lambda_{m}^{4}(\rho-1)^{4}}{P^{4}} \\
& +\frac{15116544 L_{q}^{5} T_{e}^{2} \lambda_{m}^{8}(\rho-1)^{2}}{L_{d}^{3} P^{2}} \\
& -3779136 L_{q}^{4} T_{e}^{2}\left\{\frac{\lambda_{m}^{8}(\rho-1)^{2}(\rho+1)^{2}}{L_{d}^{2} P^{2}}\right\} \\
& -\frac{45349632 L_{d}^{2} L_{q}^{2} T_{e}^{4} \lambda_{m}^{4}(\rho-1)^{4}(\rho+1)^{4}}{P^{4}} \\
& +\frac{241864704 L_{d} L_{q}^{3} T_{e}^{4} \lambda_{m}^{4}(\rho-1)^{4}(\rho+1)^{2}}{P^{4}}
\end{aligned}
$$

Substituting values of $\mathrm{L}_{\mathrm{d}}, \mathrm{L}_{\mathrm{q}}, \mathrm{P}$, and $\lambda_{\mathrm{m}}$ :

$\Delta=5.5726 \mathrm{e}-10 \mathrm{~T}_{e}^{6}-3.5588 \mathrm{e}-07 \mathrm{~T}_{e}^{4}-4.1941 \mathrm{e}-05 \mathrm{~T}_{e}^{2}$

It can be seen that $\Delta<0$ for $\mathrm{T}_{\mathrm{e}}=\{0,27 \mathrm{Nm}\}$, and $\Delta>0$ for $\mathrm{T}_{\mathrm{e}}>27 \mathrm{Nm}$ for the chosen motor. Thus, MPVA operation is feasible up to $\mathrm{T}_{\mathrm{e}}=27 \mathrm{Nm} . \Delta<0$ indicates the roots of quartic (17) being two real and two complex conjugates. Any operation beyond $\mathrm{T}_{\mathrm{e}}>27$ results in no real solution to UPF operation.

The general solution for quartic is written as:

$$
\begin{aligned}
& x_{1,2}=-\frac{b}{4 a}-S \pm 0.5 \sqrt{-4 S^{2}-2 p+\frac{q}{S}} \\
& x_{3,4}=-\frac{b}{4 a}+S \pm 0.5 \sqrt{-4 S^{2}-2 p-\frac{q}{S}}
\end{aligned}
$$

where,

$p=\frac{8 a c-3 b^{2}}{8 a^{2}}, q=\frac{b^{3}-4 a b c+8 a^{2} d}{8 a^{3}}$

$S=0.5 \sqrt{-\frac{2}{3} p+\frac{1}{3 a}\left(Q+\frac{\Delta_{0}}{Q}\right)}, Q=\sqrt[3]{\frac{\Delta_{1}+\sqrt{\Delta_{1}^{2}-4 \Delta_{0}^{3}}}{2}}$

$\Delta_{0}=c^{3}-3 b d+12 a e$

$\Delta_{1}=2 c^{3}-9 b c d+27 b^{2} e+27 a d^{2}-72 a c e$

Of the two real roots $\mathrm{x}_{3}$ and $\mathrm{x}_{4}$, it is seen that $\mathrm{x}_{3}$ satisfies eq. (16) and thus, is the required root:

$$
i_{q s}=-\frac{b}{4 a}+S+0.5 \sqrt{-4 S^{2}-2 p-\frac{q}{S}}
$$

Thus, for a required torque $T_{e}$, the quadrature axis current command is given by (19). $i_{\mathrm{ds}}$ can then be computed using (6). 

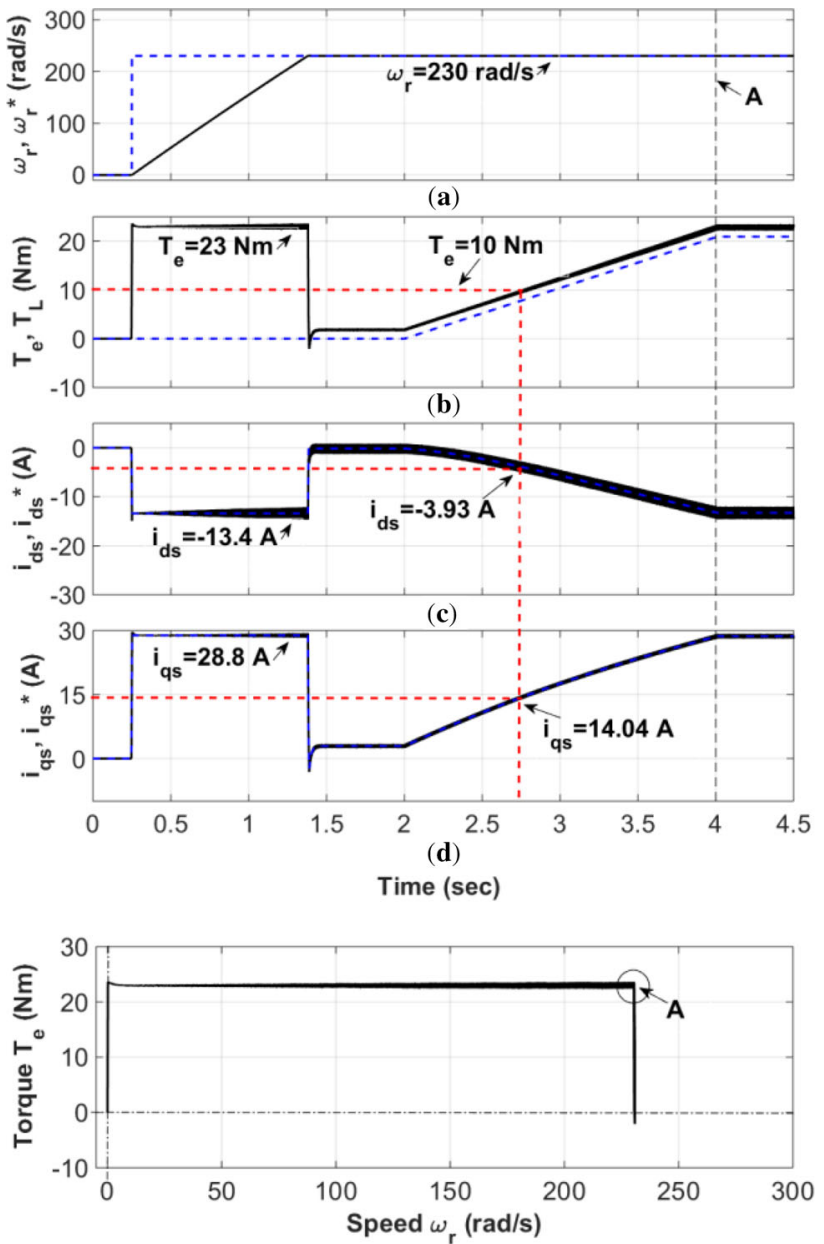

(e)

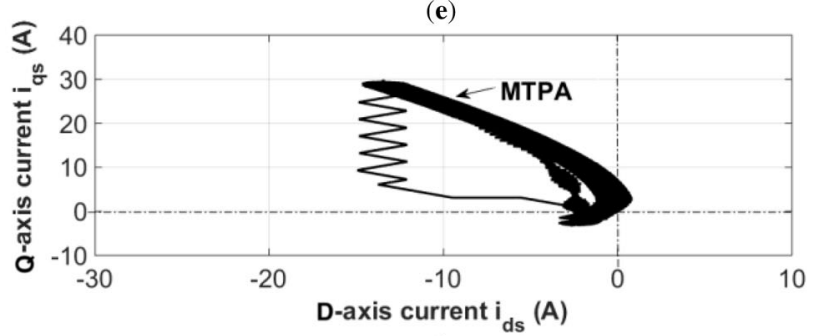

(f)

Figure 6. Simulation results following MTPA control technique. (a) Speed $\omega_{\mathrm{r}}$ and speed reference $\omega_{\mathrm{r}}{ }^{*}$, (b) Developed torque $\mathrm{T}_{\mathrm{e}}$ and load torque $\mathrm{T}_{\mathrm{L}}$, (c) $\mathrm{d}$-axis current $\mathrm{i}_{\mathrm{ds}}$ and reference $\mathrm{i}_{\mathrm{ds}} *$, (d) q-axis current $\mathrm{i}_{\mathrm{qs}}$ and reference $\mathrm{i}_{\mathrm{qs}} *$, (e) Torque-speed characteristics, and (f) $\mathrm{i}_{\mathrm{ds}}-\mathrm{i}_{\mathrm{qs}}$ trajectory followed [MTPA].

\section{Control algorithm}

The basic control block diagram is shown in figure 3 . The speed-controller defines the torque reference $T_{e}^{*}$, which in turn is converted to quadrature axis current $\mathrm{i}_{\mathrm{qs}^{-}}^{*}$ and direct axis current $i_{\mathrm{ds}}^{*}$ by use of LUT that incorporates (19) and (6) (figure 4a). The inner control loops regulate the direct and quadrature axis currents and the outer loop regulates the motor speed. Sine Pulse Width Modulation (SPWM) is

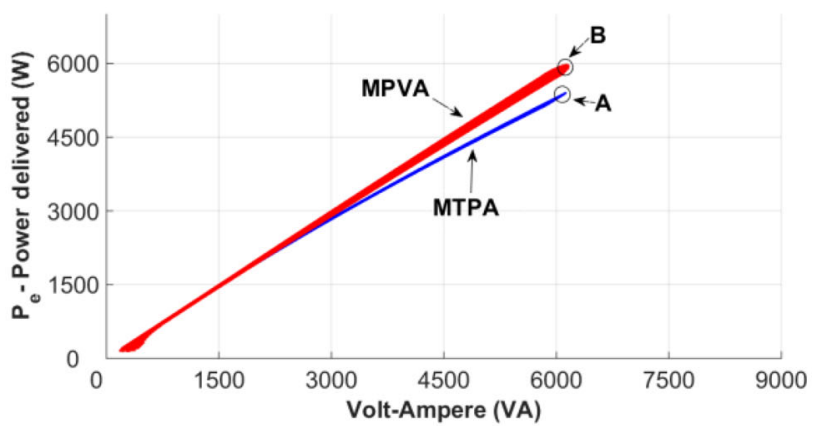

(a)
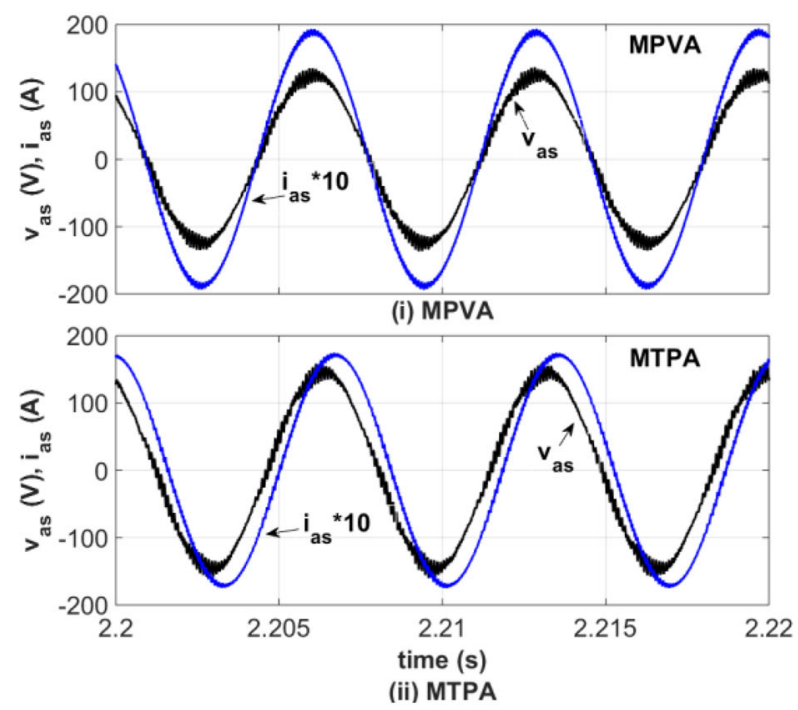

(b)

Figure 7. Comparison of MTPA and MPVA. (a) Power vs VA variation [figure 5 and figure $6(t=2-4 \mathrm{~s})$ ], and $(\mathbf{b}) \mathrm{v}_{\mathrm{as}}$ and $\mathrm{i}_{\mathrm{as}}$ at $\omega_{\mathrm{r}}=230 \mathrm{rad} / \mathrm{s}, \mathrm{Te}=17.8 \mathrm{Nm}$.

used with a maximum modulation $\mathrm{m}_{\mathrm{a}}=0.9$. The position of the rotor and speed are estimated using resolver mounted on the motor. Operation beyond rated speed or under reduction of dc-link would require field-weakening, where the point of operation would not follow MPVA trajectory rather would be along the voltage limit ellipse. The main objective of the paper is MPVA operation, therefore field weakening operation is not discussed in detail. Although, the field weakening trajectory is shown in figure 4(a) indicated by 'MPVA-FW'. Similar relation of torque-currents is shown in figure 4(b) for MTPA operation and the comparison between MTPA and MPVA is shown in figure 4(c). As seen in figure 4(c), it is clear that the MPVA operation requires larger d-axis current for a given torque in comparison to MTPA. The torque-current magnitude relation for MTPA and MPVA operation is shown in figure 4(d). As expected, operation along MTPA would provide better torque-current ratio in comparison to MPVA which optimizes power to volt-ampere ratio. 

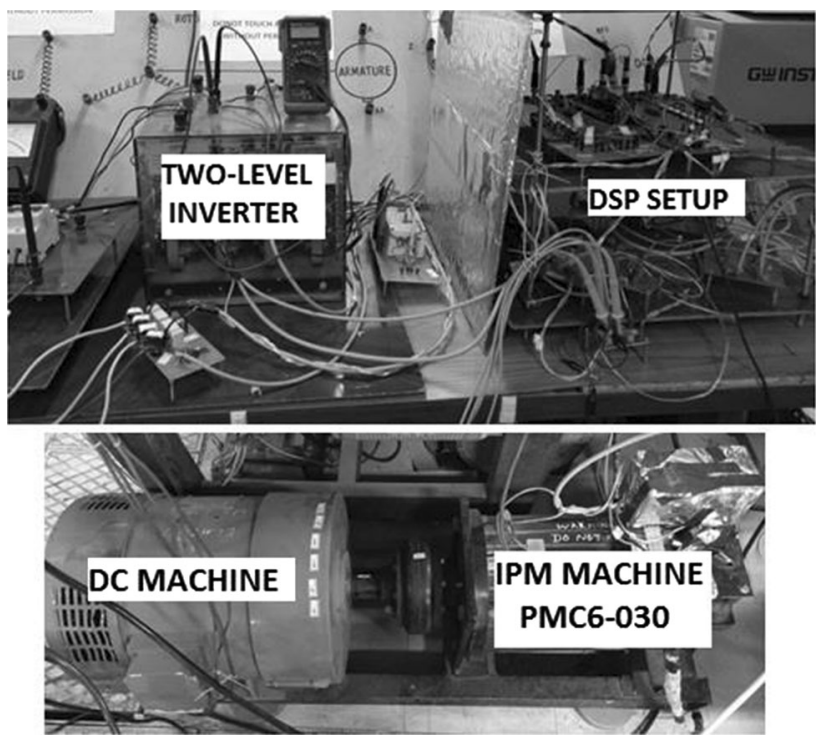

Figure 8. Experimental set-up - IPM motor coupled to DC machine, two-level inverter and DSP set-up.

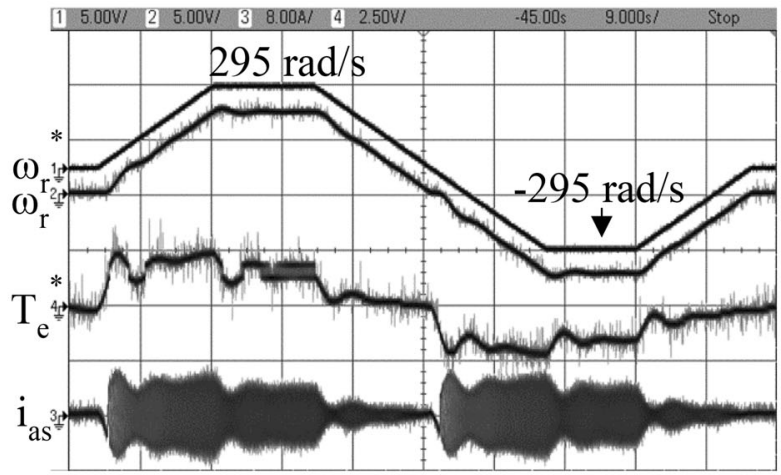

(a)

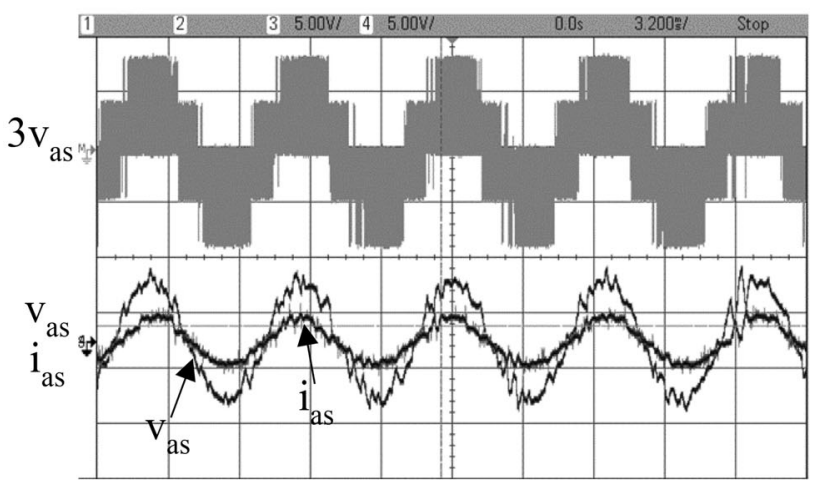

(c)

\section{Simulation results}

The IPM motor parameters are given in appendix. Simulation studies are performed in MATLAB/Simulink. The rated condition for IPM motor is operated along MTPA is indicated by ' $A$ ' (figure 2a) and along MPVA is indicated by ' $B$ ' (figure $2 b$ ). The motor parameters at ' $A$ ' - $i_{s}=15 A$, $\mathrm{V}_{\mathrm{s}}=130 \mathrm{~V}, \mathrm{~T}_{\mathrm{e}}=23 \mathrm{Nm}, \omega_{\mathrm{r}}=230 \mathrm{rad} / \mathrm{s}, \mathrm{P}_{\mathrm{r}}=290 \mathrm{~W}$. The motor parameters at ' $\mathrm{B}$ ' $\mathrm{i}_{\mathrm{s}}=5 \mathrm{~A}, \mathrm{~V}_{\mathrm{s}}=30 \mathrm{~V}, \mathrm{~T}_{\mathrm{e}}=9.6$, $\omega_{\mathrm{r}}=95 \mathrm{rad} / \mathrm{s}$, and $\mathrm{P}_{\mathrm{r}}=5782 \mathrm{~W}$. The simulation results for motor operation following MPVA are shown in figure 5 and the operation following MTPA technique are shown in figure 6. The speed response at rated speed under MPVA $\left(\omega_{\mathrm{r}}=95 \mathrm{rad} / \mathrm{s}\right)$ and MTPA $\left(\omega_{\mathrm{r}}=30 \mathrm{rad} / \mathrm{s}\right)$ is shown in figures 5(a) and 6(a) figures 5(c) and 5(d) show variation of direct axis current $i_{\mathrm{ds}}$ and quadrature axis current $\mathrm{i}_{\mathrm{qs}}$ with the application of load for operation under MPVA. The load is increased gradually starting $\mathrm{t}=2 \mathrm{~s}$ to full load at $\mathrm{t}=4 \mathrm{~s}$. The variation of $\mathrm{i}_{\mathrm{ds}}$ and $\mathrm{i}_{\mathrm{qs}}$ for motor operation along MTPA is shown in figure 6(c) and figure 6(d).

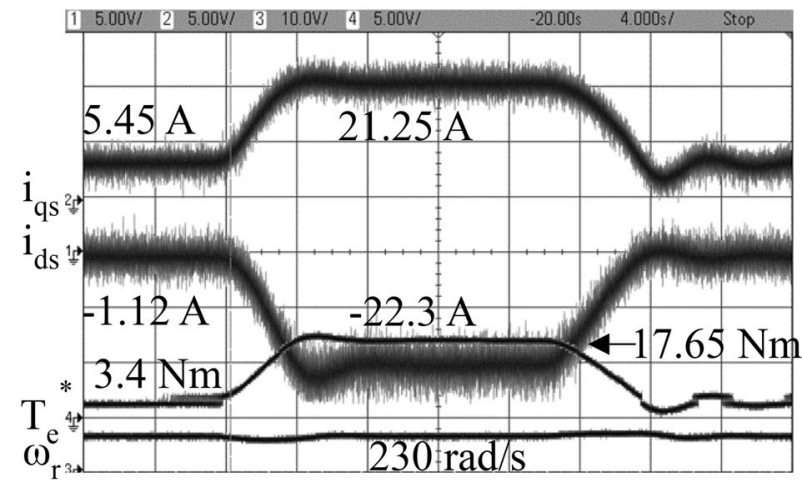

(b)

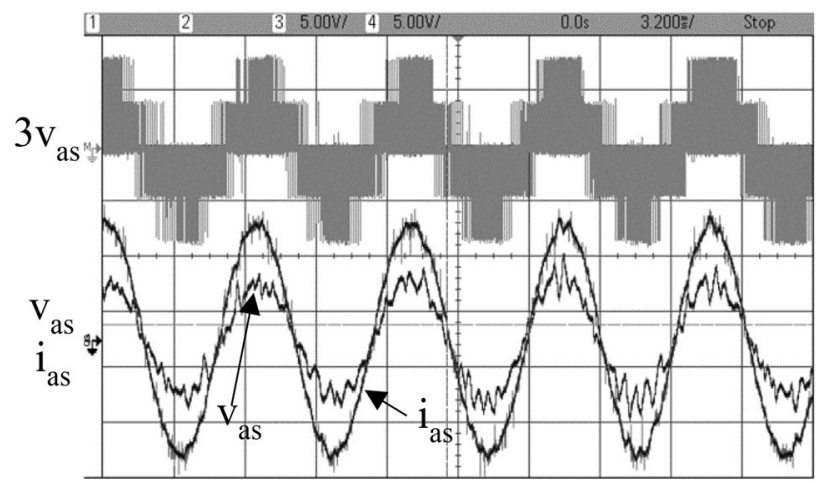

(d)

Figure 9. Experimental results of IPM motor following MPVA technique. (a) The speed response $\left[\omega_{\mathrm{r}}-200 \mathrm{rad} / \mathrm{s} / \mathrm{div}, \mathrm{T}_{\mathrm{e}}-6.8 \mathrm{Nm} / \mathrm{div}\right.$, $\mathrm{i}_{\mathrm{as}}-8 \mathrm{~A} / \mathrm{div}$, and $\left.\mathrm{t}-9 \mathrm{~s} / \mathrm{div}\right]$, (b) the variation of $\mathrm{i}_{\mathrm{ds}}$ and $\mathrm{i}_{\mathrm{qs}}$ with application of load $\left[\omega_{\mathrm{r}}-400 \mathrm{rad} / \mathrm{s} / \mathrm{div}, \mathrm{T}_{\mathrm{e}}-13.6 \mathrm{Nm} / \mathrm{div}, \mathrm{i}_{\mathrm{ds}}-10 \mathrm{~A} / \mathrm{div}, \mathrm{i}_{\mathrm{qs}}-10\right.$ $\mathrm{A} / \mathrm{div}$, and $\mathrm{t}-4 \mathrm{~s} / \mathrm{div}]$, (c) the phase voltage $\mathrm{v}_{\mathrm{as}}$ and phase current $\mathrm{i}_{\mathrm{as}}$ under no-load $\left(\omega_{\mathrm{r}}=230 \mathrm{rad} / \mathrm{s}, \mathrm{T}_{\mathrm{e}}=3.4 \mathrm{Nm}\right) *$, and $(\mathbf{d})$ the phase voltage $\mathrm{v}_{\mathrm{as}}$ and phase current $\mathrm{i}_{\mathrm{as}}$ under load $\left(\omega_{\mathrm{r}}=230 \mathrm{rad} / \mathrm{s}, \mathrm{T}_{\mathrm{e}}=17.65 \mathrm{Nm}\right)^{*}$.* :- $\left[\mathrm{i}_{\mathrm{as}}-10 \mathrm{~A} / \mathrm{div}\right.$, and $\mathrm{v}_{\mathrm{as}}-150 \mathrm{~V} / \mathrm{div}, \mathrm{V}$ as $-600 \mathrm{~V} / \mathrm{div}, \mathrm{t}-$ $3.2 \mathrm{~ms} / \mathrm{div}]$. 


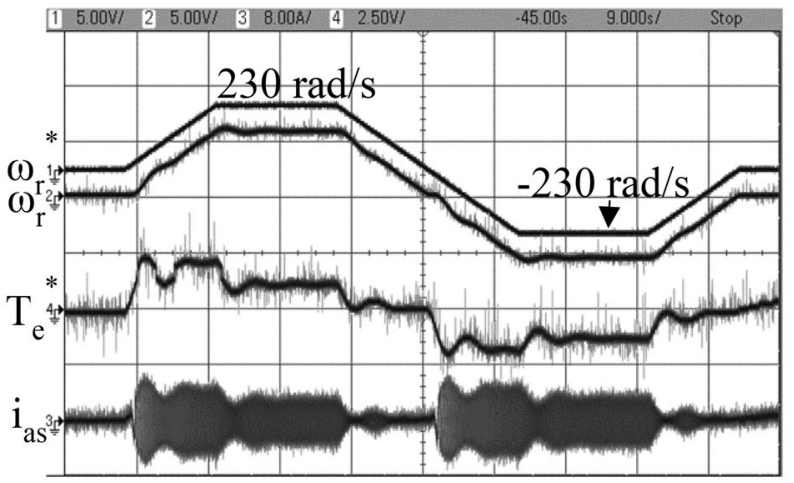

(a)

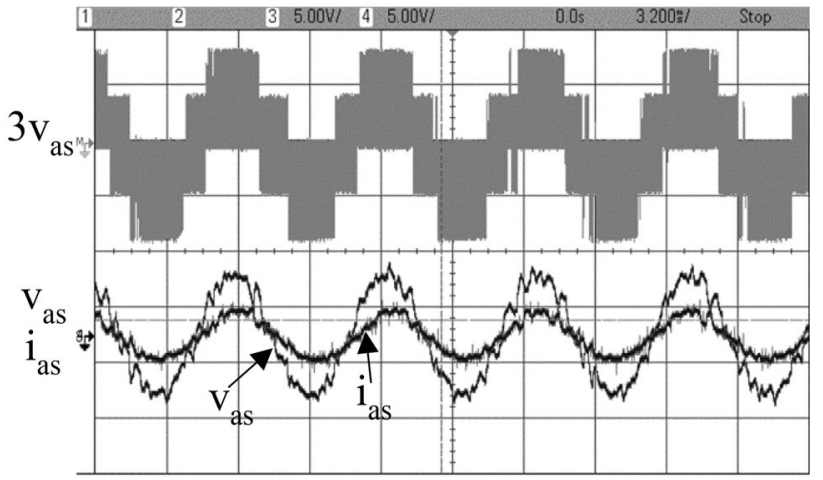

(c)

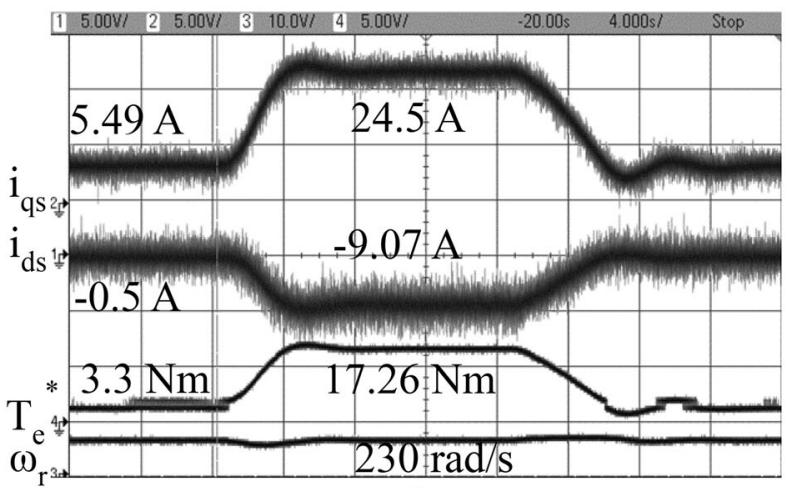

(b)

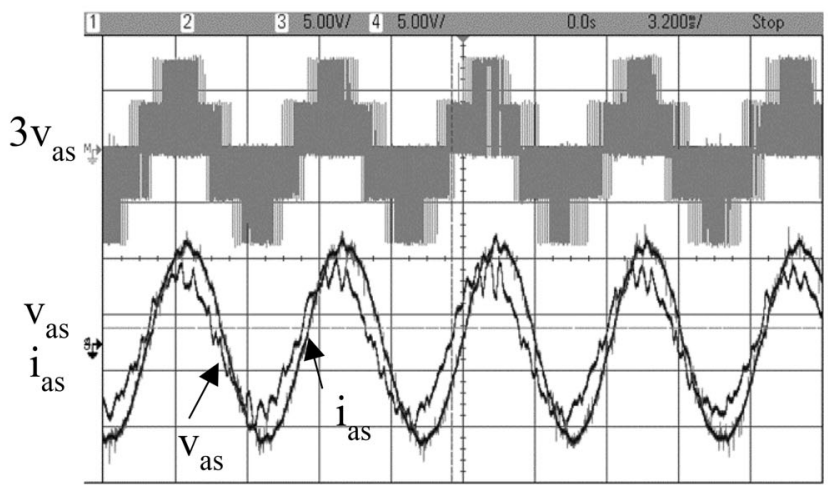

(d)

Figure 10. Experimental results of IPM motor following MTPA technique. (a) The speed response $\left[\omega_{\mathrm{r}}-200 \mathrm{rad} / \mathrm{s} / \mathrm{div}, \mathrm{T}_{\mathrm{e}}-6.8 \mathrm{Nm} / \mathrm{div}\right.$, $\mathrm{i}_{\mathrm{as}}-8 \mathrm{~A} / \mathrm{div}$, and $\left.\mathrm{t}-9 \mathrm{~s} / \mathrm{div}\right]$, (b) the variation of $\mathrm{i}_{\mathrm{ds}}$ and $\mathrm{i}_{\mathrm{qs}}$ with application of load $\left[\omega_{\mathrm{r}}-400 \mathrm{rad} / \mathrm{s} / \mathrm{div}, \mathrm{T}_{\mathrm{e}}-13.6 \mathrm{Nm} / \mathrm{div}, \mathrm{i}_{\mathrm{ds}}-10 \mathrm{~A} / \mathrm{div}, \mathrm{i}_{\mathrm{qs}}{ }^{-}\right.$ $10 \mathrm{~A} / \mathrm{div}$, and $\mathrm{t}-4 \mathrm{~s} / \mathrm{div}]$, (c) the phase voltage $\mathrm{v}_{\mathrm{as}}$ and phase current $\mathrm{i}_{\mathrm{as}}$ under no-load $\left(\omega_{\mathrm{r}}=230 \mathrm{rad} / \mathrm{s}, \mathrm{T}_{\mathrm{e}}=3.3 \mathrm{Nm}\right) *$, and $(\mathbf{d})$ the phase voltage $\mathrm{v}_{\mathrm{as}}$ and phase current $\mathrm{i}_{\mathrm{as}}$ under load $\left(\omega_{\mathrm{r}}=230 \mathrm{rad} / \mathrm{s}, \mathrm{T}_{\mathrm{e}}=17.26 \mathrm{Nm}\right) * *$ : $-\left[\mathrm{i}_{\mathrm{as}}-10 \mathrm{~A} / \mathrm{div}\right.$, and $\mathrm{v}_{\mathrm{as}}-150 \mathrm{~V} / \mathrm{div}, \mathrm{V}_{\mathrm{as}}-600 \mathrm{~V} / \mathrm{div}$, $\mathrm{t}-3.2 \mathrm{~ms} / \mathrm{div}]$.

It is seen that the MPVA operation facilitates extended constant torque region up to the operating speed of $\omega_{\mathrm{r}}=295 \mathrm{rad} / \mathrm{s}$ (figure 5e) as compared to operation along MTPA, which has maximum operating speed of $\omega_{\mathrm{r}}=230 \mathrm{rad} / \mathrm{s}$ (figure 6e). Higher operating speeds along MTPA require field-weakening (the operation would be close to MTPA though not along MTPA). Also, the maximum developed torque in MPVA is $T_{e}=19.6 \mathrm{Nm}$ and in MTPA is $T_{e}=23 \mathrm{Nm}$. The trajectory traced by direct axis current $i_{\mathrm{ds}}$ and quadrature axis current $\mathrm{i}_{\mathrm{qs}}$ with the application of load, for operation following MPVA is shown in figure 5(f). The trajectory traced by $i_{\mathrm{ds}}-i_{\mathrm{qs}}$ when the operation is following MTPA technique is shown in figure 6(f). The MPVA technique requires higher direct axis current $i_{d s}$ as compared to operation along MTPA for the same developed torque. This is shown in figure 5 and figure 6 for $\mathrm{T}_{\mathrm{e}}=10 \mathrm{Nm}$ (indicated by red-dashed lines). As seen for same developed torque of $10 \mathrm{Nm}$, the control along MPVA draws $\mathrm{i}_{\mathrm{ds}}=-7.239 \mathrm{~A}$ and $\mathrm{i}_{\mathrm{qs}}=13.5 \mathrm{~A}$, whereas when operated along MTPA the current drawn is $i_{\mathrm{ds}}=-3.93 \mathrm{~A}$ and $\mathrm{i}_{\mathrm{qs}}=114.04 \mathrm{~A}$.
The operating power factor of the IPM motor along MPVA technique is almost unity. Thus, the power delivered per VA (Volt-Ampere) [figure 5 and figure 6 $(\mathrm{t}=2-4 \mathrm{~s})]$ is higher along MPVA as compared to MTPA technique. This is seen in figure 7(a). The peak power capability i.e., the rated point of operation indicated as ' $\mathrm{B}$ ' (MPVA) is higher than the peak power at rated operation indicated as 'A' (MTPA). Here, the power and VA are estimated as: $P_{e}$ (power delivered) $=T_{e} \omega_{r}$, and VA (Volt-Ampere) $=\left.3 \quad\left|v_{\text {as }}\right|\right|_{i_{\text {as }}} \mid$. The phase voltage $v_{\text {as }}$ and phase current $i_{\text {as }}$ for IPM motor operating along MPVA and MTPA are shown in figure 7(b). The IPM motor is operated at speed $\omega_{\mathrm{r}}=230 \mathrm{rad} / \mathrm{s}$ and at a load defined by $\mathrm{T}_{\mathrm{e}}=17.8 \mathrm{Nm}$. Under similar operating conditions, it is clearly seen that the operation along MPVA trajectory is at UPF. The operation along MTPA is at a lagging power factor. Here, the fundamental phase voltage $\mathrm{v}_{\mathrm{as}}$ is obtained as: $\mathrm{v}_{\mathrm{as}}=\mathrm{m}_{\mathrm{a}} \mathrm{V}_{\mathrm{dc}} / 2$, where $\mathrm{m}_{\mathrm{a}}$ is the modulation index (defined by the reference signal) of Sine Pulse with Modulation (SPWM) and $\mathrm{V}_{\mathrm{dc}}$ is the dc-link voltage. 


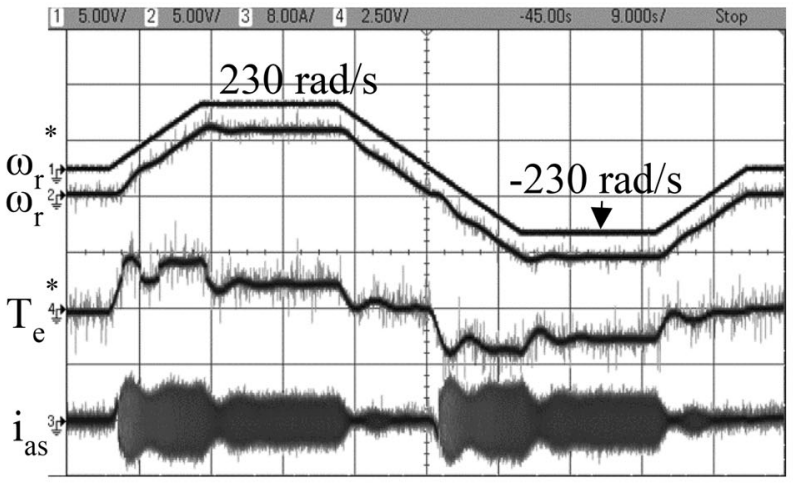

(a)

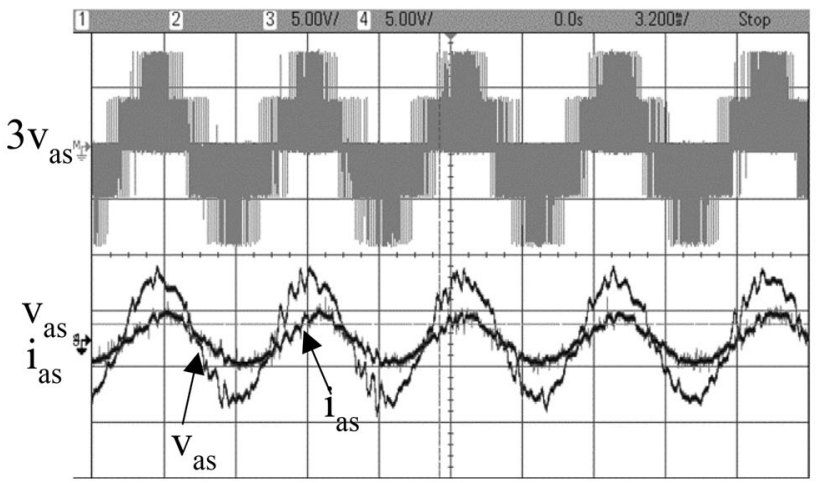

(c)

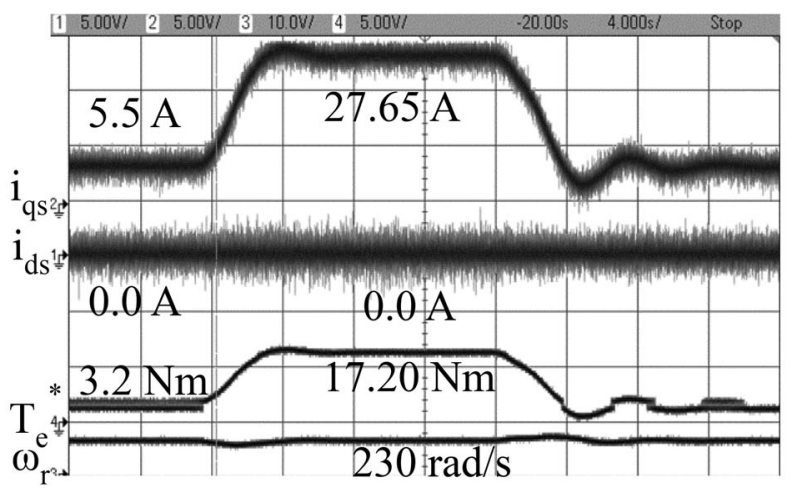

(b)

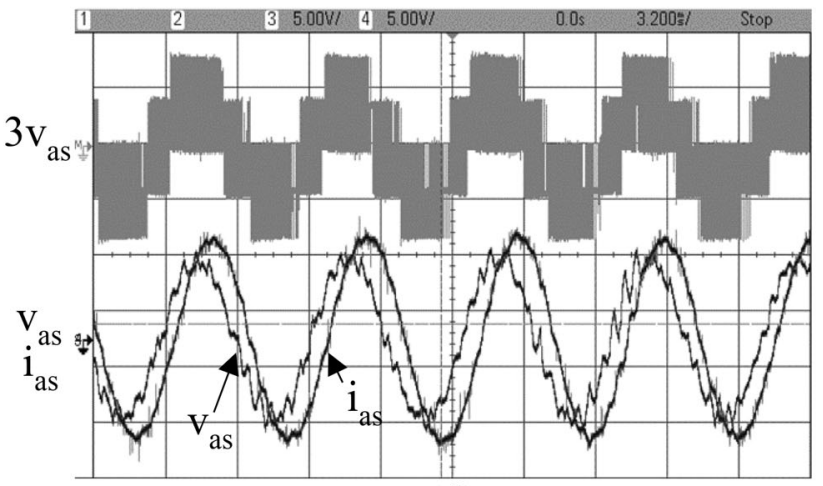

(d)

Figure 11. Experimental results of IPM motor following conventional control technique. (a) The speed response $\left[\omega_{\mathrm{r}^{-}}-200 \mathrm{rad} / \mathrm{s} / \mathrm{div}, \mathrm{T}_{\mathrm{e}}{ }^{-}\right.$ $6.8 \mathrm{Nm} / \mathrm{div}, \mathrm{i}_{\mathrm{as}}-8 \mathrm{~A} / \mathrm{div}$, and t-9 s/div], (b) the variation of $\mathrm{i}_{\mathrm{ds}}$ and $\mathrm{i}_{\mathrm{qs}}$ with application of load $\left[\omega_{\mathrm{r}}-400 \mathrm{rad} / \mathrm{s} / \mathrm{div}, \mathrm{T}_{\mathrm{e}}-13.6 \mathrm{Nm} / \mathrm{div}, \mathrm{i}_{\mathrm{ds}}{ }^{-}\right.$ $10 \mathrm{~A} / \mathrm{div}, \mathrm{i}_{\mathrm{qs}}-10 \mathrm{~A} / \mathrm{div}$, and $\left.\mathrm{t}-4 \mathrm{~s} / \mathrm{div}\right]$, (c) the phase voltage $\mathrm{v}_{\mathrm{as}}$ and phase current $\mathrm{i}_{\mathrm{as}}$ under no-load $\left(\omega_{\mathrm{r}}=230 \mathrm{rad} / \mathrm{s}, \mathrm{T}_{\mathrm{e}}=3.2 \mathrm{Nm}\right) *$, and (d) the phase voltage $\mathrm{v}_{\mathrm{as}}$ and phase current $\mathrm{i}_{\mathrm{as}}$ under load $\left(\omega_{\mathrm{r}}=230 \mathrm{rad} / \mathrm{s}, \mathrm{T}_{\mathrm{e}}=17.20 \mathrm{Nm}\right) *{ }^{*}:-\left[\mathrm{i}_{\mathrm{as}}-10 \mathrm{~A} / \mathrm{div}\right.$, and $\mathrm{v}_{\mathrm{as}}-150 \mathrm{~V} / \mathrm{div}, \mathrm{V}_{\mathrm{as}}{ }^{-}$ $600 \mathrm{~V} / \mathrm{div}, \mathrm{t}-3.2 \mathrm{~ms} / \mathrm{div}]$.

\section{Experimental results}

The experiments have been performed on an Interior Permanent Magnet motor by Moog Inc. The $\mathrm{m}=$ otor is a Moog Pitch Motor developed for wind-turbines, Model PMC6-030. The motor parameters are mentioned in the appendix. The experimental setup is shown in figure 8 . The setup comprises of the IPM motor coupled to a dc-machine. The dc-machine is operated as a generator to load the IPM motor. The system is controlled using a TMS320F28335 which is a low cost dsp controller from Texas Instruments. Sine Pulse Width Modulation (SPWM) is used with a maximum modulation index of 0.9 and switching frequency of $10 \mathrm{KHz}$.

The experimental results are shown in figures 9-12. Comparison of motor operation along MPVA and MTPA technique is established by simulation results. The experiments demonstrate detailed comparison of the proposed MPVA technique, the MTPA technique and also the conventional control strategy. Conventional control strategy refers to the IPM motor being operated with direct axis current $i_{d s}=0$, where only the quadrature axis current $i_{q s}$ is utilized to develop torque. The speed response of the motor, variation of direct-axis current $\mathrm{i}_{\mathrm{ds}}$ and quadrature axis current $\mathrm{i}_{\mathrm{qs}}$ on application of load, the phase voltage $\mathrm{v}_{\mathrm{as}}$ and the phase current $i_{\text {as }}$ are shown in figure 9, figure 10, and figure 11 for MPVA, MTPA and conventional control, respectively. The dc-link is maintained at $\mathrm{V}_{\mathrm{dc}}=500 \mathrm{~V}$ to cater the voltage-requirement for conventional control strategy $\left(\omega_{\mathrm{r}}=230 \mathrm{rad} / \mathrm{s}, \mathrm{T}_{-\mathrm{e}}=19.5 \mathrm{Nm}, \mathrm{v}_{\mathrm{s}}=150 \mathrm{~V}, \mathrm{i}_{\mathrm{s}-}\right.$ $=15 \mathrm{~A})$. The rated dc-link voltage for MPVA $\left(\omega_{\mathrm{r}-}\right.$ $\left.=295 \mathrm{rad} / \mathrm{s}, \mathrm{T}-\mathrm{e}_{\mathrm{e}}=19.6 \mathrm{Nm}, \mathrm{v}_{\mathrm{s}}=130 \mathrm{~V}, \mathrm{i}_{\mathrm{s}}=15 \mathrm{~A}\right)$ and MTPA $\left(\omega_{\mathrm{r}}=230 \mathrm{rad} / \mathrm{s}, \quad \mathrm{T}_{-\mathrm{e}}=23 \mathrm{Nm}, \mathrm{v}_{\mathrm{s}}=130 \mathrm{~V}, \mathrm{i}_{\mathrm{s}-}\right.$ $=15 \mathrm{~A})$ technique is $\mathrm{V}_{\mathrm{dc}}=425 \mathrm{~V}$.

As expected, the direct axis current $i_{\mathrm{ds}}$, is higher along MPVA in comparison to MTPA technique for required torque. This is seen in figure 9(b) and figure 10(b). The conventional control strategy maintains $\mathrm{i}_{\mathrm{ds}}=0$, unless operation in field-weakening is required (figure 11b). Thus, a higher quadrature axis current component $\mathrm{i}_{\mathrm{qs}}$ is drawn for same developed torque in comparison to MTPA and MPVA technique. Also, the direct axis current $\mathrm{i}_{\mathrm{ds}}$, is higher for 


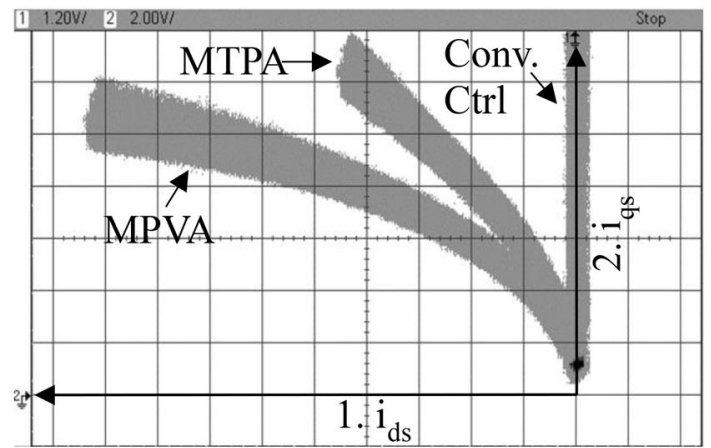

(a)

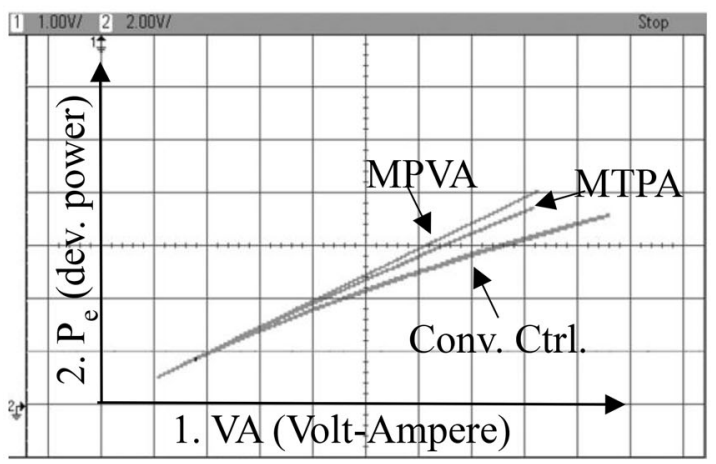

(c)

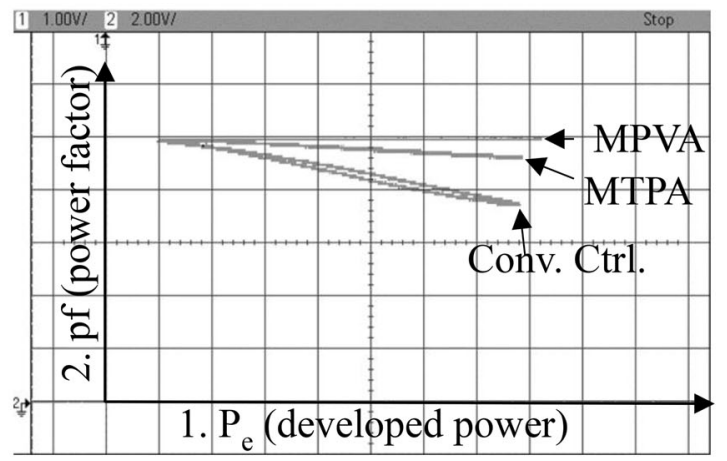

(b)

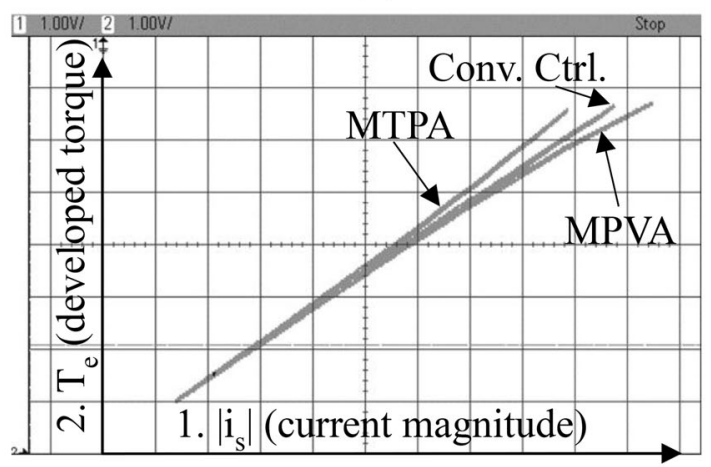

(d)

Figure 12. Experimental results showing comparison of the three control techniques: $(\mathbf{a}) \mathrm{i}_{\mathrm{ds}}-\mathrm{i}_{\mathrm{qs}}$ trajectory traced with the application of load [ $\mathrm{i}_{\mathrm{ds}}-2.4 \mathrm{~A} / \mathrm{div}$, and $\left.\mathrm{i}_{\mathrm{qs}^{-}}-4 \mathrm{~A} / \mathrm{div}\right]$, (b) pf (power factor) vs $\mathrm{P}_{\mathrm{e}}$ (developed power) $\left[\mathrm{P}_{\mathrm{e}}-600 \mathrm{~W} /\right.$ div, and pf-0.2/div], (c) $\mathrm{P}_{\mathrm{e}}(\mathrm{developed}$ power) vs VA (volt-ampere) $\left[\mathrm{P}_{\mathrm{e}}-1200 \mathrm{~W} / \mathrm{div}\right.$, and VA-600 VA/div], and (d) $\mathrm{T}_{\mathrm{e}}$ (developed torque) vs $\mathrm{i}_{\mathrm{s}} \mathrm{I}$ (current magnitude) $\left[\mathrm{T}_{\mathrm{e}}{ }^{-}\right.$ $2.72 \mathrm{Nm} / \mathrm{div}$, and $\left.\mathrm{li}_{\mathrm{s}} \mathrm{l}-2 \mathrm{~A} / \mathrm{div}\right]$.

MPVA technique as compared to MTPA. These results can be correlated to simulation results shown in figure 5 and figure 6 .

The phase voltage $\mathrm{v}_{\mathrm{as}}$ and the phase current $\mathrm{i}_{\mathrm{as}}$ under noload are shown in figure 9(c), figure 10(c) and figure 11(c) for operation along MPVA, MTPA and conventional control, respectively. Both, the PWM voltage $\mathrm{v}_{\text {as }}$ $\left(3 \mathrm{v}_{\mathrm{as}}=\mathrm{v}_{\mathrm{ab}}-\mathrm{v}_{\mathrm{ca}}\right)$ measured at motor terminals and the fundamental phase voltage estimated using the reference wave of SPWM are shown. Here $\mathrm{v}_{\mathrm{as}}=0.5 \mathrm{~V}_{\mathrm{dc}} \mathrm{v}_{\mathrm{asc}}$, where $\mathrm{V}_{\mathrm{dc}}$ is the dc-link voltage and $\mathrm{v}_{\mathrm{asc}}$ is the reference signal of SPWM corresponding to phase A. As the motor is at noload, the power factor under the three control techniques is almost unity, slightly lagging when operation is along MTPA and conventional control. If the load is increased, the power factor of IPM motor operated along MPVA is almost unity. On the other hand, the power factor for operation along MTPA and conventional control is lagging. Though operation along MTPA is at a better power factor condition than the conventional control strategy. This is shown in figure 9(d), figure 10(d) and figure 11(d), where the $\mathrm{v}_{\text {as }}$ and $\mathrm{i}_{\text {as }}$ are shown for operation along MPVA, MTPA and $\mathrm{co}=$ nventional control respectively.
It is possible to change the control strategy online when the IPM motor is in running condition. A detailed comparison of the operation along different control techniques is demonstrated. The trajectory traced by direct axis current $\mathrm{i}_{\mathrm{ds}}$ and quadrature axis current $\mathrm{i}_{\mathrm{qs}}$ with the application of load is shown in figure 12(a). These trajectories correspond to experimental results shown in figure 9(b), figure 10(b) and figure 11(b). These trajectories can be correlated to simulation results shown in figure 5(f) and figure 6(f). The conventional control trajectory is traced along $\mathrm{q}$-axis as $\mathrm{i}_{\mathrm{ds}}=0$. The MPVA trajectory and MPVA trajectory have non-zero direct axis current $i_{\mathrm{ds}}$.

figure 12 also shows the variation of developed power, power factor, VA, current magnitude and developed torque for operation along MPVA, MTPA and conventional control. The IPM motor is operated at speed $\omega_{\mathrm{r}}=230 \mathrm{rad} / \mathrm{s}$ and the load is gradually increased from $\mathrm{T}_{\mathrm{e}}=3.5 \mathrm{Nm}$ to $\mathrm{T}$-e$=17.5 \mathrm{Nm}$ to demonstrate the variation of power developed per VA. figure 12(b) shows the variation of power factor with developed power $\mathrm{P}_{\mathrm{e}}$. As expected the operation along MPVA is at almost UPF ( $\mathrm{pf}=0.97)$. The operation at

MTPA is at a lower power factor and even lower operational power factor is observed under conventional control 
strategy. The power factor along MTPA and conventional control deteriorates with increase in load. Whereas, the operation is maintained at almost UPF irrespective of load condition under MPVA technique. Improved power factor implies better power to VA ratio. This can be seen in figure 12(c) which shows the variation of power developed $\mathrm{P}_{\mathrm{e}}$ with the VA drawn. Operating along MPVA technique delivers higher power for a given VA in comparison to MTPA and conventional control. This can be correlated to simulation results as shown in figure 7(a).

Figure 12(d) shows the variation of developed torque T-e with the current magnitude. The operation along MTPA technique draws the least current for a given load, as the control is optimized to operate at maximum torque per ampere. The operation along MPVA technique is optimized to draw minimum VA product. It is seen that the current magnitude under MPVA technique is higher as compared to MTPA and conventional control, though the voltage requirement is reduced thus making the VA product minimum. The voltage and current magnitudes for MPVA, MTPA and conventional control can be compared as seen in figure 9(d), figure 10(d), and figure 11(d), respectively. Here, the power, VA, voltage magnitude and current magnitude are estimated as:

$$
\begin{gathered}
\left|v_{s}\right|=\frac{2}{3} \sqrt{v_{d s}^{2}+v_{q s}^{2}} \\
\left|i_{s}\right|=\frac{2}{3} \sqrt{i_{d s}^{2}+i_{q s}^{2}} \\
P_{e}=\frac{2}{3}\left[v_{d s} i_{d s}+v_{q s} i_{d s}\right] \\
V A=\frac{3}{2}\left[\left|v_{s}\right|\left|i_{s}\right|\right], \text { and } \\
p f=\frac{P_{e}}{V A}
\end{gathered}
$$

\section{Concluding remarks}

Unity power factor operation of IPM motor, referred to as Maximum Power Per VA operation of IPM motor, was proposed. The MPVA control technique facilitates maximum volt-ampere utilization of the drive-system. The MPVA control also enables extended constant torque region up to a higher operating speed in comparison to the MTPA technique. MPVA control has higher peak power capability and higher operating speed for a given rating of IPM motor as compared to MTPA control. Though, the maximum torque capability along MPVA control is slightly sacrificed.

The detailed mathematical model of IPM motor along MPVA control was developed and the solution to the 4th order quartic was derived. The solution was utilized to developed a LUT for experimental demonstration of vector controlled IPM motor along MPVA. Detailed comparison of MPVA, MTPA and conventional control (refers to the control strategy similar to SMPM motor where only $\mathrm{i}_{\mathrm{qs}}$ is utilized to develop torque) was established and shown experimentally. The experimental results clearly demonstrated that the operation along MPVA control was at almost unity power factor irrespective of the load, whereas the power factor for operation along MTPA and conventional control deteriorate with load.

MTPA technique optimizes torque per ampere while MPVA technique optimizes power per volt-ampere. For torque-controlled drives MTPA would be preferred as it optimizes the torque/current ratio. MPVA operation would be preferred for applications that demand maximum VA utilization such as wind-energy systems or any power generation application.

\section{List of symbols}

$\mathrm{r}_{\mathrm{s}} \quad$ stator resistance $(\Omega)$

$\mathrm{L}_{\mathrm{d}} \quad \operatorname{direct}(\mathrm{d})$-axis inductance $(\mathrm{H})$

$\mathrm{L}_{\mathrm{q}} \quad$ quadrature(q)-axis inductance $(\mathrm{H})$

$\lambda_{\mathrm{m}} \quad$ P.M. flux linkage (wb)

$\mathrm{v}_{\mathrm{ds}} \quad \mathrm{d}$-axis stator voltage $(\mathrm{V})$

$\mathrm{v}_{\mathrm{qs}} \quad \mathrm{q}$-axis stator voltage $(\mathrm{V})$

$\mathrm{i}_{\mathrm{ds}} \quad \mathrm{d}$-axis stator current (A)

$\mathrm{i}_{\mathrm{qs}} \quad \mathrm{q}$-axis stator current $(\mathrm{A})$

$\lambda_{\mathrm{ds}} \quad \mathrm{d}$-axis stator flux linkage (wb)

$\lambda_{\mathrm{qs}} \quad \mathrm{q}$-axis stator flux linkage (wb)

$\omega_{\mathrm{e}}$ rotor speed in electrical $\mathrm{rad} / \mathrm{s}$

$\omega_{\mathrm{r}} \quad$ rotor speed in mechanical $\mathrm{rad} / \mathrm{s}$

$\theta_{\mathrm{e}} \quad$ rotor position (rad)

$\mathrm{T}_{\mathrm{e}} \quad$ electrical torque developed (Nm)

$\lambda_{\mathrm{s}_{-} \mathrm{r}}$ rated stator flux $(\mathrm{wb})$

$\mathrm{i}_{\mathrm{s} \_\mathrm{r}}$ rated stator current (A)

$\mathrm{V}_{\mathrm{dq}}$ rated voltage peak in dq-frame $(\mathrm{V})$

$\rho \quad$ saliency ratio

\section{Appendix}

The motor parameters are: $\mathrm{L}_{\mathrm{d}}=3.2 \mathrm{mH}, \mathrm{L}_{\mathrm{q}}=8 \mathrm{mH}$, $\mathrm{r}_{\mathrm{s}}=0.244 \Omega, \lambda_{\mathrm{m}}=0.156 \mathrm{wb}, \mathrm{P}=8$. The rms current and voltage rating is taken as: $i_{\mathrm{s}}=15 \mathrm{~A}$ and $\mathrm{v}_{\mathrm{s}}=130 \mathrm{~V}$. Rated speed $\omega_{\mathrm{r}}=230 \mathrm{rad} / \mathrm{s}$ and rated torque $\mathrm{T}_{\mathrm{e}}=23 \mathrm{Nm}$ [Moog make].

\section{References}

[1] Jahns T M, Kliman G B and Thomas Neumann W 1986 Interior permanent-magnet synchronous motors for adjustable-speed drive. IEEE Trans. Ind. Appl. 22(4): 738-747 
[2] Jahns T M 1987 Flux-weakening regime operation of an interior permanent-magnet synchronous motor drive. IEEE Trans. Ind. Appl. 23(4): 681-689

[3] Morimoto S, Sanada M and Takeda Y 1994 Wide-speed operation of interior permanent magnet synchronous motors with high-performance current regulator. IEEE Trans. Ind. Appl. 30(4): 920-926

[4] Bae B-H, Patel N, Schulz S and Sul S-K 2003 New field weakening technique for high saliency interior permanent magnet motor. In: Conference on Indsutry Application, pp. 898-905

[5] Jung S-Y, Hong J and Nam K 2013 Current minimizing torque control of the IPMSM using ferrari's method. IEEE Trans. Power Electron. 28(12): 5603-5617

[6] Lee J, Nam K, Choi S and Kwon S 2009 Loss-minimizing control of PMSM with the use of polynomial approximations. IEEE Trans. Power Electron. 24(4): 1071-1082

[7] Consoli A, Scelba G, Scarcella G and Cacciato M 2013 An effective energy-saving scalar control for industrial IPMSM drives. IEEE Trans. Ind. Electron. 60(9): 3658-3669

[8] Schiferl R F and Lipo T A 1990 Power capability of salient pole permanent magnet synchronous motors in variable speed drive applications. IEEE Trans. Ind. Appl. 26 (1): 115-123

[9] Moussa M F, Helal A, Gaber Y H and Youssef A 2008 Unity power factor control of permanent magnet motor drive system. In: International Conference on Power System, Aswan, 2008, pp. 360-367

[10] Solution to quartic functions. https://en.wikipedia.org/wiki/ Quartic_function. Accessed January 52015.

[11] Foo G H B and Zhang X 2016 Constant switching frequency based direct torque control of interior permanent magnet synchronous motors with reduced ripples and fast torque dynamics. IEEE Trans. Power Electron. 31(9): 6485-6493

[12] Zhong L, Rahman M F, Hu W Y and Lim K W 1997 Analysis of direct torque control in permanent magnet synchronous motor drives. IEEE Trans. Power Electron. 12(3): $528-536$
[13] Rahman M F, Zhong L and Lim K W 1998 A direct torquecontrolled interior permanent magnet synchronous motor drive incorporating field weakening. IEEE Trans. Ind. Appl. 34(6): 1246-1253

[14] Inoue T, Inoue Y, Morimoto S and Sanada M 2015 Mathematical model for MTPA control of permanent-magnet synchronous motor in Stator flux linkage synchronous frame. IEEE Trans. Ind. Appl. 51(5): 3620-3628

[15] Kallio S, Karttunen J, Peltoniemi P, Silventoinen P and Pyrhonen O 2014 Determination of the inductance parameters for the decoupled d-q model of double-star permanentmagnet synchronous machines. IET Electric Power Appl. 8(2): 39-49

[16] Agarlita S C, Coman C E, Andreescu G D and Boldea I 2013 Stable V/f control system with controlled power factor angle for permanent magnet synchronous motor drives. IET Electric Power Appl. 7(4): 278-286

[17] Pellegrino G, Armando E and Guglielmi P 2012 Direct-flux vector control of IPM motor drives in the maximum torque per voltage speed range. IEEE Trans. Ind. Electron. 59(10): 3780-3788

[18] Wallmark O, Galic J and Mosskull H 2012 Sensorless control of permanent-magnet synchronous motors adopting indirect self-control. IET Electric Power Appl. 6(1): 12-18

[19] Hoang K D, Ren Y, Zhu Z Q and Foster M 2015 Modified switching-table strategy for reduction of current harmonics in direct torque controlled dual-three-phase permanent magnet synchronous machine drives. IET Electric Power Appl. 9(1): 10-19

[20] Guo H, Wu Z, Qian H, Yu K and Xu J 2015 Statistical analysis on the additional torque ripple caused by magnet tolerances in surface-mounted permanent magnet synchronous motors. IET Electric Power Appl. 9(3): 183-192

[21] Hekmati P, Yazdanpanah R and Mirsalim M 2015 Design and analysis of double-sided slotless axial-flux permanent magnet machines with conventional and new stator core. IET Electric Power Appl. 9(3): 193-202 